\title{
Research on Performance Evaluation System of Manufacturing Listed Companies Based on CNN
}

\author{
Zhang Chengwei ${ }^{1, a}$ \\ ${ }^{1}$ China University of Mining and Technology (Beijing) \\ a2140707259@qq.com \\ *Corresponding author
}

\begin{abstract}
.
From the perspective of studying and evaluating the operating performance of enterprises, this paper chooses a system including, but not limited to, financial indicators. Based on this, in view of the uncertainty of the coupling between the evaluation indicators, a performance evaluation model of state-owned pillar manufacturing enterprises based on convolutional neural network (CNN) was established. Specific performance data from 2016 to 2018 of many representative companies in China's listed entity manufacturing industry is selected as training and testing samples for neural networks. Finally, The trained CNN neural network is applied to the current evaluation and simulation prediction of corporate performance. The empirical analysis results in this paper have achieved satisfactory results.
\end{abstract}

Keywords: convolutional neural network, key indicators, performance evaluation

\section{Introduction}

The value of the enterprise value is judged from the performance of the enterprise and the dynamic performance of the market during the long-term operating cycle of the enterprise. The traditional financial performance-based enterprise performance evaluation system can no longer meet the requirements. This article uses mathematical statistics to quantitatively analyze specific financial indicator data. Qualitative analysis of non-financial indicators is combined.A scientific indicator system is selected and a performance evaluation system according to certain procedures is established. In the performance evaluation system, the fuzzy comprehensive evaluation method is subject to large subjective factors, while the objective evaluation method has poor extrapolation capabilities such as entropy weight and factor analysis, and the basis for weight allocation is not the characteristics of the data in the actual performance evaluation[1]. In view of the uncertainty of the coupling between indicators and the non-linear correlation between input and output, this paper establishes an objective and credible convolutional neural network performance evaluation model with strong extrapolation ability. The performance evaluation results can be obtained quickly and accurately through the input of indicators.

The article mainly selects a number of comprehensive data including financial data from 2016 to 2018 of 31 physical manufacturing companies listed in China as sample data for simulation training. During the training, a performance evaluation model of manufacturing enterprises based on convolutional neural network (CNN) was established, and the standardized index is used as the input of the CNN network and a fitting effect is obtained, and a scientific performance evaluation system with reference value is established.

\section{Principles and methods of performance evaluation of listed companies}

\subsection{Entropy method}

Entropy weight was first introduced by Claude Elwood Shannon to information theory, and has been widely used in socio-economic fields. The basic idea of entropy weight method is to determine the objective weight according to the variability of the index ${ }^{[2]}$.In general, if the information entropy of an indicator $E_{j}$ which is smaller, This indicator indicates the greater the degree of variation in the value, and the more information is provided, the greater the role it can play in the evaluation of the indicator, This indicator shows that the weight is also greater. On the contrary, the larger the information entropy of an indicator, the smaller the degree of variation of the indicator in the comprehensive evaluation, the less the amount of information provided, the smaller the role it plays in the comprehensive evaluation, The weight of information entropy will become smaller. The entropy weighting steps are shown below.

\subsubsection{Data standardization}

Standardize the data of each indicator. Assume that the original decision matrix of the indicator is. 


\subsubsection{Determine the weight of each indicator}

$$
X=\left[\begin{array}{cccc}
x_{11} & x_{12} & \cdots & x_{1 n} \\
x_{21} & x_{22} & \cdots & x_{2 n} \\
\vdots & \vdots & \vdots & \vdots \\
x_{m 1} & x_{m 2} & \cdots & x_{m n}
\end{array}\right]
$$

Where $m$ is the number of companies and $n$ is the number of indicators.

The standardized indicator matrix is.

$$
Y=\left[\begin{array}{cccc}
y_{11} & y_{12} & \cdots & y_{1 n} \\
y_{21} & y_{22} & \cdots & y_{2 n} \\
\vdots & \vdots & \vdots & \vdots \\
y_{m 1} & y_{m 2} & \cdots & y_{m n}
\end{array}\right]
$$

Let the number of the $i$ company be the original and normalized values of the $j$ index $x_{i j}$ and $y_{i j}$, respectively.

The normalized formula is.

$$
y_{i j}=\frac{x_{i j}-x_{j}^{\min }}{x_{j}^{\max }-x_{j}^{\min }}
$$

The normalized formula for negative indicators is.

$$
y_{i j}=\frac{x_{j}^{\max }-x_{i j}}{x_{j}^{\max }-x_{j}^{\min }}
$$

The standardized formula for the fitness index is.

$$
y_{i j}=\left\{\begin{array}{cc}
1-\frac{q_{1}-x_{i j}}{\max \left(q_{1}-x_{j}^{\min }, x_{j}^{\max }-q_{2}\right)}, & x_{i j}<q_{1} \\
1 & q_{1} \leq x_{i j} \leq q_{2} \\
1-\frac{x_{i j}-q_{2}}{\max \left(q_{1}-x_{j}^{\min }, x_{j}^{\max }-q_{2}\right)}, & x_{i j}>q_{2}
\end{array}\right.
$$

Where, $q_{1}$ and $q_{2}$ are the lower and upper limits of the appropriate range, respectively.

\subsubsection{Information entropy of each indicator in the formula}

According to the definition of information entropy in information theory $E_{j}=-\ln (m)^{-1} \sum_{i=1}^{m} \mathrm{p}_{i j} \ln p_{i j}$, the information $p_{i j}=y_{\mathrm{ij}} / \sum_{i=1}^{m} y_{i j}$ entropy of a set of data. Where, $\lim _{p_{m} \rightarrow 0} p_{i j} \ln p_{i j}=0$ is defined if $p_{i j}=0$
We calculate the information entropy of each indicator according to the calculation formula of information entropy $E_{1}, E_{2}, E_{3} \cdots E_{n}$. Calculate the weight of each indicator through information entropy: $W_{j}=\frac{1-E_{j}}{k-\sum E_{j}}(j=1,2, \cdots n)$

\subsection{TOPSIS method}

The TOPSIS method was first proposed by C $\cdot$ L $\cdot$ Hwang and $\mathrm{K}$. Yoon in 1981. The TOPSIS method is based on the closeness of a limited number of evaluation objects to the idealized target. [3]. The TOPSIS method is a sorting method that approximates the ideal solution. The TOPSIS algorithm steps are as follows.

\subsubsection{Construct a weighted normal matrix} $C=\left(c_{i j}\right)_{m \times n}$ and set the weight vector determined $W=\left[w_{1}, w_{2}, \cdots w_{n}\right]^{T}$ by the entropy weight

$$
c_{i j}=w_{j} \times b_{i j}, i=1,2, \cdots m ; j=1,2, \cdots n
$$

\subsubsection{Determine positive ideal solution and} negative ideal solution $C^{*}, C^{0}$

Positive ideal solution $c_{j}^{*}=\left\{\begin{array}{c}\max _{i} c_{i j}, j \text { is a cost attribute (the larger the better) } \\ \min _{i} c_{i j}, j \text { is the benefit attribute (the smaller the better) }\end{array}\right.$

Negative ideal solution $c_{j}^{0}=\left\{\begin{array}{c}\max _{i} c_{i j}, j \text { is a cost attribute (the larger the better) } \\ \min _{i} c_{\ddot{y}}, j \text { is the benefit attribute (the smaller the better) }\end{array}\right.$

\subsubsection{Calculate the distance from each solution} to the positive (negative) ideal solution

Distance to positive ideal solution

$$
\mathrm{s}_{i}^{*}=\sqrt{\sum_{j=1}^{n}\left(c_{i j}-c_{j}^{*}\right)^{2}}, i=1,2, \cdots m
$$

Distance to negative ideal solution

$$
\mathrm{s}_{i}^{0}=\sqrt{\sum_{j=1}^{n}\left(c_{i j}-c_{j}^{0}\right)^{2}}, i=1,2, \cdots m
$$


2.2.4 Calculate the distance of the comprehensive evaluation value

$$
f_{i}^{*}=\frac{s_{i}^{0}}{s_{i}^{0}+s_{i}^{*}}, i=1,2, \cdots m
$$

\begin{abstract}
A convolutional neural network consists of an input-output layer, a convolutional layer, a pooling layer, and a fully connected layer. The structure of the convolutional neural network is shown in Figure 1 [4-5]. A set of input data is calculated by convolution to obtain the output of the convolution the output of the pooling layer is obtained by downsampling, and then the final network output result is obtained through the full connection.
\end{abstract}

\section{CONSTRUCTIONOFCONVOLUTIONALNEURAL NETWORKPERFORMANCEEVALUTIONMODEL}

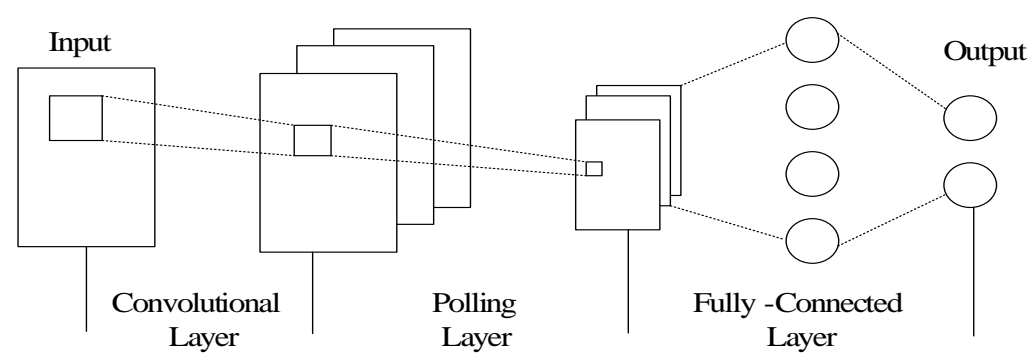

Fig. 1. Convolutional neural network structure

The input layer of this paper is the index decision matrix. The convolution operation is performed after three $3 \times 3$ convolution kernels with a step size of 1 . The initial weight and offset terms use the msra method to satisfy the Gaussian distribution. The activation function uses the relu function. The convolution result is a feature map with a depth of 3 layers. Suppose $x_{i j}$ represents the $i$ row and $j$ column of the input matrix, $w_{n m}$ represents the $\mathrm{m}$ row and $\mathrm{n}$-th column weight value of each filter template, $w_{b}$ represents the bias term of each convolution kernel, and $y_{i j}$ represents the convolution output of each layer The convolution result of the $i$ row and the $j$ column of the feature map. The activation function is $\mathrm{f}$. The convolution calculation formula is shown in formula (8).

$$
y_{i j}=f\left(\sum_{m=0}^{2} \sum_{n=0}^{2} w_{m n} x_{i+m, j+n}+w_{b}\right)
$$

The pooling layer is a downsampling operation on the result of the convolutional layer. The depth of the feature map after downsampling is the same as the depth of the feature map before downsampling, and the number of feature map samples per layer is reduced. The filter template used for downsampling in this paper, the downsampling function uses the mean function, and the final downsampling result is a 3-layer $2 \times 2$ feature map. The down-sampling operation formula is shown in equation (9).

$$
x_{j}^{l}=f\left(\beta_{j}^{l} \operatorname{down}\left(x_{j}^{l-1}\right)+b_{j}^{l}\right)
$$

Down () in the formula represents the downsampling function, $\beta$ represents a weighting coefficient, and $\mathrm{b}$ represents an offset term. $x_{j}^{l}$ represents the $j$-th feature map of the $l$-th layer after downsampling.

Convolution and downsampling operations enable local connections and weight sharing. Each layer of neurons is only connected to some neurons in the previous layer, and the weight of the filter is the same for all neurons in the previous layer. Compared with the full connection of the traditional BP neural network, the number of parameters is greatly reduced .

The calculation of the fully connected layer takes the output of the pooling layer as an input for calculation. The fully connected layer structure is shown in Fig 2 [6]. 


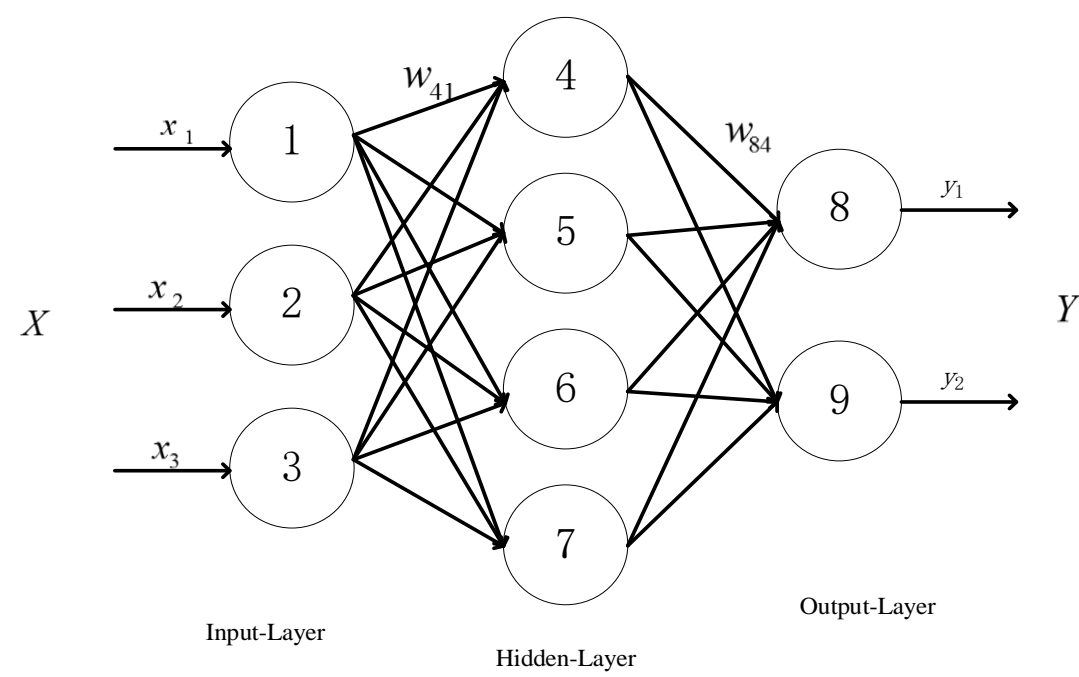

Fig. 2. Fully connected neural network

Assume that the weight matrix of a layer in the fully connected layer is $W$, the input vector is $X$, and the output vector is $\mathrm{Y}$. The fully connected formula is shown in equation (10).

$$
Y=f(W \cdot X)
$$

The weight training formula for the fully connected layer is shown in equation (11)

$$
w_{j i}=w_{j i}+\eta \delta_{j} x_{j i}
$$

Where $w_{i j}$ is the weight from node $i$ to node $j, \eta$ is the learning rate, $\delta_{j}$ is the error term for node $j$, and $x_{j i}$ is the input passed from node $i$ to node $j$.

The calculation formula for the error term $\delta_{i}$ of the hidden layer node is shown in the formula.

$$
\delta_{i}=a_{i}\left(1-a_{i}\right) \sum_{k \in \text { outputs }} w_{k i} \delta_{k}
$$

where, $a_{i}$ is the output value of node $i, w_{k i}$ is the connection weight of node $i$ to its next layer node $k$, and $\delta_{k}$ is the error term of node i's next layer node.

The calculation formula for the error term $\delta_{i}$ of the output layer node $i$ is shown in equation (13).

$$
\delta_{i}=y_{i}\left(1-y_{i}\right)\left(t_{i}-y_{i}\right)
$$

where $\delta_{i}$ is the error term of node $i, y_{i}$ is the output value of node, and $t_{i}$ is the target value of the sample corresponding to node $i$.

For the convolutional layer error transfer formula is shown in equation (14).

$$
\delta^{l-1}=\sum_{d=0}^{D} \delta_{d}^{l} * W_{d}^{l} \times f^{\prime}\left(n e t^{l-1}\right)
$$

It represents the depth, $\delta^{l-1}$ represents the error term of the layer, W represents the weight, $f$ represents the activation function, and net represents the weighted input of the neuron, which is the product of the weight and the input.
The error term transfer formula for the pooling layer is shown in equation (15).

$$
\delta^{l-1}=\delta^{l} \otimes\left(\frac{1}{n^{2}}\right)_{n \times n}
$$

The formula for calculating the weight gradient of the convolution layer is shown in equation (16).

$$
\nabla f=\sum_{m} \sum_{n} \delta_{m n} a_{i+m, j+n}^{l-1}
$$

The gradient calculation formula for the bias term is shown in Equation (17).

$$
\nabla f=\sum_{i} \sum_{j} \delta_{i j}^{l}
$$

The weight training algorithm of the convolutional layer still uses the gradient descent algorithm.

\section{APPLICATIONOF CONVOLUTIONAL NEURAL NETWORKPERFORMANCEEVALUATIONMODEL}

\subsection{Data sources}

The data used in this article are mainly from Juchao Information, Hexun Finance, China Securities Industry Association, and National Bureau of Statistics. Then through the analysis, the financial and non-financial data of 31 listed companies in the physical manufacturing industry were obtained for sample analysis.

\subsection{Index selection}

According to the actual situation of the listed company's physical manufacturing industry, the three indicators that reflect the company's debt situation are selected: the current ratio (appropriateness indicator), the debt service ratio (positive indicator), and the liability (negative indicator); 
the indicators that reflect the profitability of the company are selected. 4 including income (positive indicator), cost (negative indicator), return on net assets (positive indicator), gross profit of main business (positive indicator); 5 indicators reflecting the company's operating capabilities are selected, including Net cash flow from operating activities (positive indicator), turnover ratio of current assets (positive indicator), days of inventory sales (suitability indicator), earnings per share (positive indicator), operating cash flow per share (positive indicator), Three indicators reflecting corporate financial risk, including long-term debt ratio (negative indicators), asset-liability ratio (appropriateness indicator), equity ratio (appropriateness indicator); three indicators reflecting corporate value growth ability, including main business Growth rate (positive indicator), net asset growth rate (positive indicator), net profit growth rate (suitability indicator).

The codes of each indicator are current ratio D1, debt service ratio $\mathrm{D} 2$, and debt $\mathrm{D} 3$; income $\mathrm{P} 1$, cost $\mathrm{P} 2$, return on net assets $\mathrm{P} 3$, main income gross profit $\mathrm{P} 4$; net cash flow from operating activities $\mathrm{O} 1$, and turnover ratio of current assets $\mathrm{O} 2$, Inventory sales days $\mathrm{O} 3$, earnings per share $\mathrm{O} 4$, operating cash flow per share $\mathrm{O5}$, indicators reflecting corporate financial risk, long-term debt ratio $F$, asset-liability ratio $\mathrm{F} 2$, equity ratio $\mathrm{F} 3$; indicators reflecting corporate value growth ability, main business growth rate $\mathrm{G} 1$, Net asset growth rate $\mathrm{G} 2$, net profit growth rate G3

The listed entity manufacturing companies are selected are Jinzhi Technology, Weihai Guangtai, Telga, Hikvision, Yuyue Medical, BOE, Julun Intelligent, Guoguang Optoelectronics, BYD, Gree Electric, Yinlun Shares, Sunlord Electronics, Topband, Western Materials, Hanzhong Precision Machinery, Changal Group, Jiangte Electric, AVIC, Yunhai Metal, Founder Motor, Goldwind Technology, Tech-Long, Midea Group, Topsun New Energy, Benai, Xiyi Co., Ltd., Tianrun Crankshaft, Xingsen Technology, Jinzhou Pipeline, Songzhi Co., Ltd., and Robot.

The indicators of the entity manufacturing industry of 31 listed companies are shown in Table 1.

Table 1. List of company indicators

\begin{tabular}{|c|c|c|c|}
\hline $\begin{array}{l}\text { Evaluation } \\
\text { dimension }\end{array}$ & Performance indicator & Operational metrics & Index properties \\
\hline \multirow{4}{*}{ Debt situation } & Current ratio D1 & Current ratio $=$ current assets $/$ current liabilities & $\begin{array}{l}\text { Appropriateness } \\
\text { index }\end{array}$ \\
\hline & Debt service ratio D2 & $\begin{array}{l}\text { Debt principal repayment ratio = annual profit after } \\
\text { tax / (debt principal / debt life })\end{array}$ & Positive indicator \\
\hline & Liability D3 & Liability during the evaluation cycle & Negative indicator \\
\hline & Income P1 & Operating income during the evaluation period & Positive indicator \\
\hline \multirow{3}{*}{ Profitability } & Cost P2 & Operating costs during the evaluation period & Negative indicator \\
\hline & Return on equity P3 & Return on equity $=$ Net profit $/$ Net assets & Positive indicator \\
\hline & Main income gross profit $\mathrm{P} 4$ & Main business gross profit / main business income & Positive indicator \\
\hline \multirow{5}{*}{$\begin{array}{l}\text { Operational } \\
\text { capability }\end{array}$} & $\begin{array}{l}\text { Net cash flow from operating } \\
\text { activities O1 }\end{array}$ & $\begin{array}{l}\text { Refers to the cash flow from operations minus the } \\
\text { increase in operating capital. }\end{array}$ & Positive indicator \\
\hline & $\begin{array}{c}\text { Turnover rate of current } \\
\text { assets } \mathrm{O} 2\end{array}$ & $\begin{array}{l}\text { Turnover rate of current assets (times) }=\text { net income } \\
\text { from main operations / average total current assets }\end{array}$ & Positive indicator \\
\hline & Inventory sales days $\mathrm{O} 3$ & $\begin{array}{c}\text { Average days of mass production inventory sales } \\
\text { during the period }\end{array}$ & $\begin{array}{l}\text { Appropriateness } \\
\text { index }\end{array}$ \\
\hline & Earnings per share $\mathrm{O} 4$ & Refers to the ratio of profit after tax / total equity & Positive indicator \\
\hline & $\begin{array}{l}\text { Operating cash flow per } \\
\text { share O5 }\end{array}$ & $\begin{array}{l}\text { Operating cash flow per share = Net operating cash } \\
\text { flow / Number of outstanding common shares in } \\
\text { circulation Positive indicator }\end{array}$ & Positive indicator \\
\hline \multirow{3}{*}{ Financial risk } & Long-term debt ratio $\mathrm{F} 1$ & $\begin{array}{c}\text { Refers to debts with a repayment period of one year } \\
\text { or more. }\end{array}$ & Negative indicator \\
\hline & Asset-liability ratio F2 & Asset-liability ratio $=$ total debt $/$ total assets & $\begin{array}{l}\text { Appropriateness } \\
\text { index }\end{array}$ \\
\hline & Equity ratio $\mathrm{F} 3$ & Equity ratio $=$ total debt $/$ owner's equity & $\begin{array}{l}\text { Appropriateness } \\
\text { index }\end{array}$ \\
\hline \multirow{3}{*}{$\begin{array}{l}\text { Ability to } \\
\text { grow }\end{array}$} & $\begin{array}{l}\text { Growth rate of main business } \\
\text { G1 }\end{array}$ & $\begin{array}{l}\text { Growth rate of main business income = (Main } \\
\text { business income for the current period-Main } \\
\text { business income for the previous period) / Main } \\
\text { business income for the previous period }\end{array}$ & Positive indicator \\
\hline & Net asset growth rate $\mathrm{G} 2$ & $\begin{array}{l}\text { Net asset growth rate }=(\text { (end-period net } \\
\text { assets-beginning of net assets }) \text { / opening net assets })\end{array}$ & Positive indicator \\
\hline & Net profit growth rate G3 & $\begin{array}{l}\text { Growth rate of net profit }=\text { (net profit of the current } \\
\text { period-net profit of the previous period) / net profit } \\
\text { of the previous period }\end{array}$ & $\begin{array}{l}\text { Appropriateness } \\
\text { index }\end{array}$ \\
\hline
\end{tabular}


performance scores of 31 companies calculated by the TOPSIS method are shown in Table 2.

\subsection{Nnalysis of Performance Evaluation Results}

We obtain the weight of each index through the entropy weight method, and the 31-year comprehensive

Table 2. TOPSIS performance results

\begin{tabular}{|c|c|c|c|}
\hline $\begin{array}{c}\text { Year } \\
\text { Company Name }\end{array}$ & 2016 & 2017 & 2018 \\
\hline Jinzhi Technology & 0.472999746 & 0.614521028 & 0.503178161 \\
\hline Weihai Guangtai & 0.396974137 & 0.35929412 & 0.218390966 \\
\hline Telga & 0.22767483 & 0.178054981 & 0.151666856 \\
\hline Hikvision & 0.729476815 & 0.7117759 & 0.688337453 \\
\hline BOE & 0.74534658 & 0.860723823 & 0.851462005 \\
\hline Yuyue Medical & 0.610146653 & 0.502181224 & 0.484862256 \\
\hline Giant Wheel Intelligence & 0.887396834 & 0.891590669 & 0.869377038 \\
\hline Guoguang & 0.852230467 & 0.868592275 & 0.86636709 \\
\hline BYD & 0.849985861 & 0.882276604 & 0.889408757 \\
\hline Gree Electric & 0.851621286 & 0.879641033 & 0.867628104 \\
\hline Yinlun shares & 0.846024666 & 0.849292212 & 0.857036783 \\
\hline Sunlord Electronics & 0.844586305 & 0.851260055 & 0.851629955 \\
\hline Topbon shares & 0.805220891 & 0.857134283 & 0.858495894 \\
\hline Western material & 0.767861302 & 0.894095568 & 0.879366626 \\
\hline Hanbell Precision & 0.871048109 & 0.859878546 & 0.869743379 \\
\hline Chang Aluminum & 0.840199151 & 0.881905161 & 0.891460838 \\
\hline Jiangte Motor & 0.779903623 & 0.891832458 & 0.858722658 \\
\hline AVIC & 0.821418701 & 0.831353987 & 0.822647478 \\
\hline Yunhai Metal & 0.798350919 & 0.85073816 & 0.846144375 \\
\hline Founder Motor & 0.8688855 & 0.878938649 & 0.88978763 \\
\hline Goldwind Technology & 0.778785602 & 0.829043559 & 0.834422637 \\
\hline Technolog & 0.885081208 & 0.894259844 & 0.877344803 \\
\hline Midea Group & 0.881816128 & 0.88809305 & 0.884819482 \\
\hline Topsun New Energy & 0.870262856 & 0.877038865 & 0.887643169 \\
\hline punai shares & 0.881025312 & 0.888017425 & 0.858553216 \\
\hline Xiyi shares & 0.872005904 & 0.821195714 & 0.885790005 \\
\hline Tianrun crankshaft & 0.866609032 & 0.863026887 & 0.855766815 \\
\hline Xingsen Technology & 0.845436813 & 0.870702424 & 0.860311017 \\
\hline Jinzhou Pipeline & 0.863500538 & 0.857997891 & 0.844195115 \\
\hline Songzhi shares & 0.853293483 & 0.846475298 & 0.869839863 \\
\hline robo & 0.881108213 & 0.881941955 & 0.820412181 \\
\hline
\end{tabular}

The established enterprise performance evaluation system based on the convolutional neural network model was trained, and the performances of the first two years of 31 listed companies in the physical manufacturing industry were selected as training samples. 


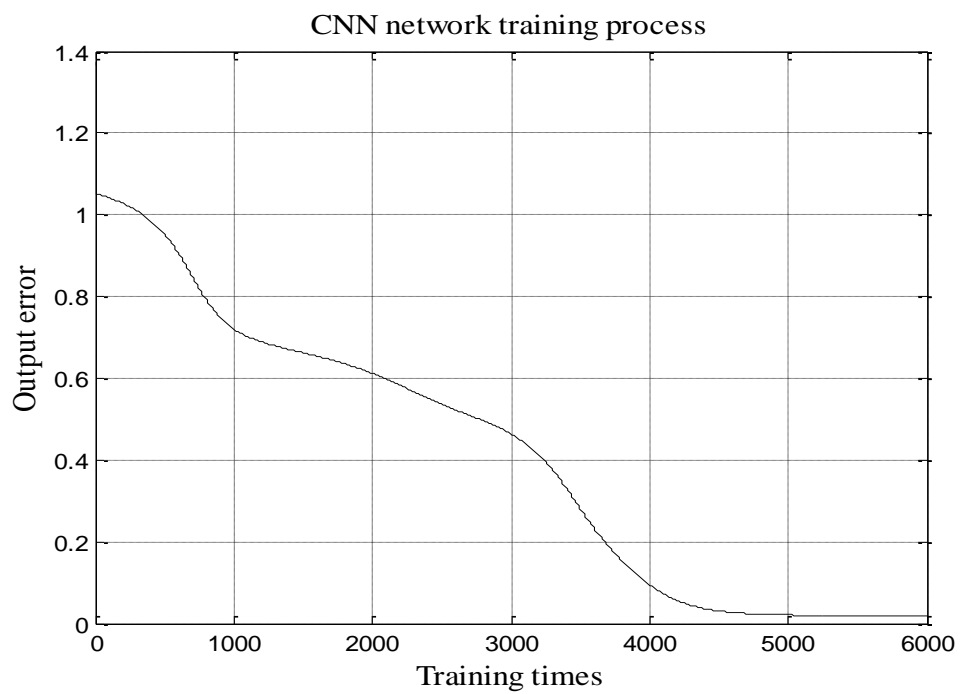

Fig. 3. Convolutional neural network training process

According to the figure, the results tend to converge after training to about 5100 generations. The performance evaluation fitting of the 18-year data of 31 listed companies using the simulated training $\mathrm{CNN}$ network model is shown in Fig 4.

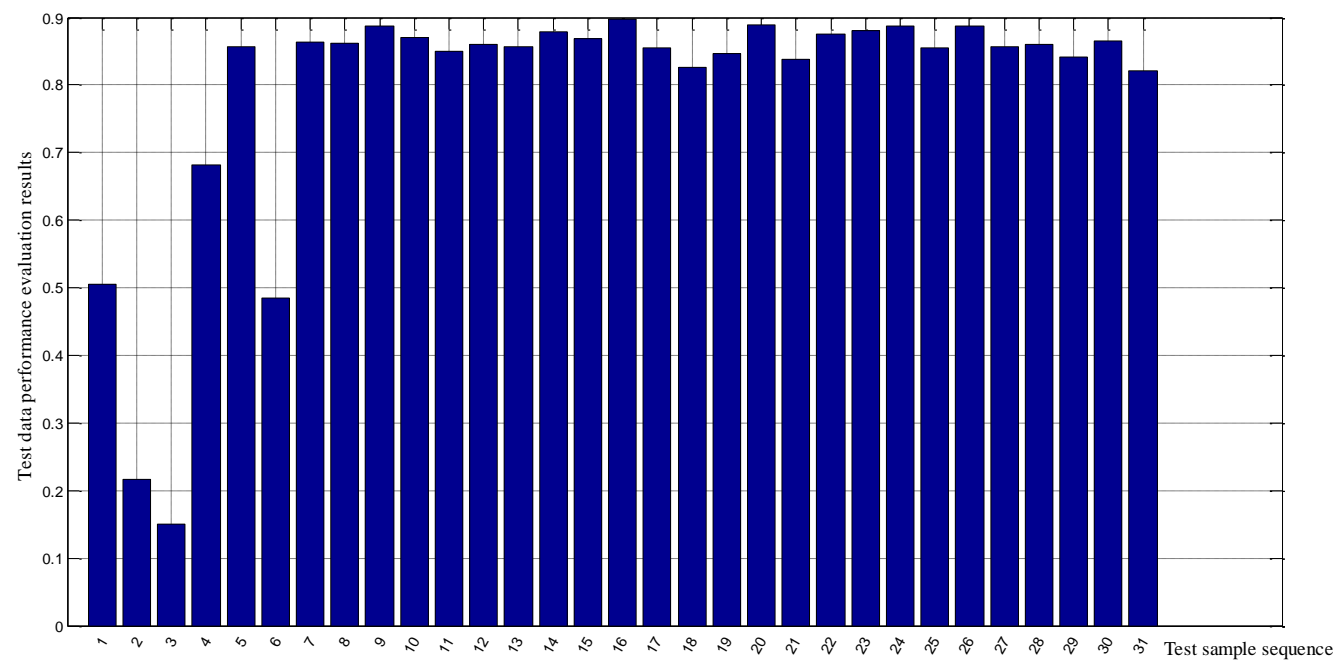

Fig. 4. CNN performance evaluation model test data results

It can be seen from the figure that the performance comparison of each company is obvious. The performance of the $9,16,20$, and 24 companies is better. The error curve of the test results of 31 listed companies is shown in Fig 5. 


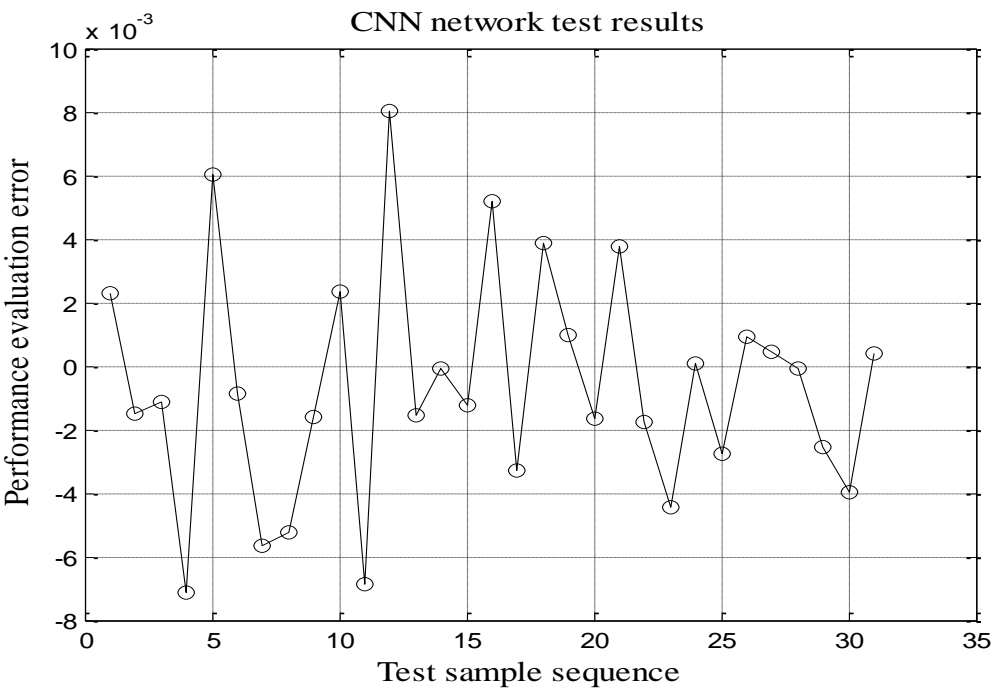

Fig. 5. Test sample error curve

It can be seen from the figure that the comprehensive performance evaluation results of listed entity manufacturing industry companies using the convolutional neural network performance evaluation system model fit the actual situation.

\section{CONCLUSION}

Based on the analysis and summary of the performance evaluation methods of existing listed companies in the manufacturing industry, and combined with the application research on the convolutional neural network model, Then, this paper conducts empirical research using sample data of listed manufacturing companies. Convolutional neural network effectively solves the nonlinear relationship between the input and output of the performance evaluation system. Compared with the BP neural network model, it effectively solves the problem of uncertain correlation between performance indicators and reduces the number of parameters. Compared with the performance evaluation system established by the traditional subjective and objective weighting method, the convolutional neural network model expands the generalization ability and improves the extrapolation and robustness. In this paper, the performance evaluation system index is given in detail and the principle of convolutional neural network and its application in performance evaluation system are analyzed in detail. Finally, the model of convolutional neural network performance evaluation system is established, and the model is simulated. the final experimental results prove that it can perform performance evaluation well. The method of this paper provides a new idea for the comprehensive performance evaluation model of enterprises.

\section{REFERENCES}

[1] Shaohui Zou, Zhili Ding, Xiaogang Wang. Performance Evaluation of Listed Coal Chemical companies in China:a Study Based on Factor Analysis[J]. Journal of Science of Teachers College \& University, 2018.

[2] NaLi, Xiaodong Li. Importance of Green Packaging Evaluation Index Based on AHP-entropy Weigh.Packaging Engineering, 2019, 40(15):144-149.

[3] Xia Wang, Qingquan Duan. Improved AHP-TOPSIS model for the comprehensive risk evaluation of oil and gas pipelines [J]. Petroleum Science, 2019(16).

[4] ZHOU Fei-Yan, JIN Lin-Peng, DONG Jun. Review of Convolutional Neural Network[J]. Chinese Journal of Computers, 2017.

[5] Rize Jin, Liangfu Lu, Joomin Lee. Multi-representational convolutional neural networks for text classification[J]. Computational Intelligence, 2019(11).

[6] Ou, Jun, Li, Yujian. Vector-kernel convolutional neural networks[J]. NEUROCOMPUTING, 2019. 